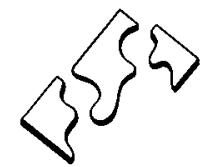

\title{
Philosophical Thinking in Young Children ${ }^{1}$
}

\section{Gareth Matthews}

University of Massachusetts

There are many perplexities one gets into when one tries to reason counterfactually. Among the difficulties counterfactual conditionals raise, no problems are more knotty, and seemingly intractable, than those raised by counterfactual identity statements. If person $a$ were person $b$ then .... If Verdi had been Brahms, would he have written symphonies instead of operas, or would La Forza del Destino, "The Power of Destiny," have been, in its original version, Die Macht des Schicksals? If Ronald Reagan were Franklin D. Roosevelt, a man Reagan claims to admire, would we now be having a new New Deal, or would we, because of Reaganomics, never have made it out of the Great Depression?

The study of counterfactual reasoning belongs, of course, to philosophy. In fact it is an area of philosophy in which there has been considerable, even remarkable, recent progress. So I have introduced half my topic, "Philosophical Thinking": now for the other half, "Young Children.”

Steve, three years old, recently watched his father eat a banana. "You don't like bananas, do you, Steve?" said the father."No," replied Steve. "If you wuz me," he went on, "you wouldn't like bananas either." Steve paused to reflect. "Then," he added after a minute, "who would be the daddy?"

This anecdote is interesting for several reasons. One thing that makes it interesting is the way it shows the child comparing different points of view- the father's, from which bananas are something likeable, versus his own, from which they are not. Piaget had led us to suppose that children much older than this three-year-old were bound by their egocentricity and unable, constitutionally unable, to consider more than one point of view. Being unable to consider even a second point of view, they are unable, according to what Piaget told us, to recognize that their own point of view is a point of view; that is, is simply one of many possible vantage points from which the world may be observed and assessed.

If we made explicit the implicit reasoning that is brought out by this anecdote, we might get something like this:

1. Anybody who wuz me would like what I like and would not like what I don't like.

2. I don't like bananas.

3. Anybody who wuz me wouldn't like bananas.

4. In particular, if Daddy wuz me, he wouldn't like bananas.

I realize that attributing such reasoning to a mere three-year-old goes against the thrust of much recent work in developmental psychology, even when one adds the caveat that the reasoning is implicit, rather than 
explicit. But my reply to that is ... so much the worse for the thrust of much recent work in developmental psychology.

Whatever you say about my reconstruction of Steve's reasoning up to this point, there is really no blinking the fact that he has, quite naturally and spontaneously, hit upon a genuine and fascinating worry about counterfactual identity statements. If $a$ were $b$, who would be $a$ ? If I were Robert Coles, who would be me? Robert Coles? My wife might be pleased; she might not.

Or perhaps this is closer to Steve's worry. You and I have different roles to play. You, let's say, are the daddy; I am the kid. But if you were me, who would there be to play the daddy-role?

I want to turn now to another anecdote. Consider the following exchange:

Maxine: You know, cheese is made of grass.

Teacher: Why do you say that?

Maxine: Because cheese is made of milk and cows give milk and cows eat grass.

Teacher: Do you eat cheese?

Maxine: Yeah.

Teacher: Then are you made of grass, too?

Maxine: No, I'm a human.

This conversation is a somewhat abridged version of a real exchange between a child and a teacher. I used it recently in a course I was teaching on philosophy and children. Many of the students in that course were school teachers from Boston public and parochial schools. Almost all were participants in a special program in critical thinking. These were people with a commitment to teaching, people who care deeply about children, and people who also care a great deal about thinking.

I gave the Maxine fragment to my students at the beginning of my course and asked about ten of them to write a short paper in which they would try to say how they might continue the conversation with Maxine.

At the next class meeting the students read their response papers aloud to the rest of the class, and we discussed them together. Some papers were solemn and didactic. Some showed a sense of fun. Some were rather formal, whereas others were free and imaginative.

Most of the writers picked up the idea that Maxine thought human beings stand apart from the animal world. Some wanted Maxine to realize that we share with beasts an animal nature; that we are, after all, human animals. Others wanted to explore with Maxine what is special and distinctive about human beings; they wanted to develop with her the insight that we have a nature we do not share with beasts. 
Whatever line these students took on the last part of the Maxine fragment, though, they were in overwhelming agreement that Maxine's first statements display some sort of logical howler. Some said they wished they could explain the mistake to her but didn't know how to proceed. One expressed the hope that she might be able to help Maxine better after she had taken my course. Others thought they knew what the mistake was, though, in fact, they were not successful in identifying a mistake.

Some members of my class thought that, according to Maxine if $x$ eats $y$, then, unless $x$ is a human, $x$ is made of $y$. This is the principle that, unless you are a human being, you are what you eat. The trouble with this as the basis for reconstruction of Maxine's reasoning is that Maxine never says that cows are made of grass. It's "cheese" that she says is made of grass. And her reason for saying cheese is made of grass is that cheese is made of milk and cows give milk and cows eats grass. Thus we have these four statements:

1. Cows eat grass.

2. Cows give milk.

3. Cheese is made of milk.

4. Cheese is made of grass.

Why should anyone think the last statement, "cheese is made of grass," follows from the others? The obvious answer, it seems to me, is that the first two are thought to support the intermediate conclusion,

(2.5) Milk is made of grass.

and that that, together with "(3) Cheese is made of milk," yields, by a principle of transitivity,

(4) Cheese is made of grass.

(Thus: Milk is made of grass; cheese is made of milk; therefore cheese is made of grass.)

Is the made-of relation really transitive? I'm inclined to think so, though I have some worries. If it is, the inference I have attributed to Maxine is a good one.

What now about the first inference, the one from

1. Cows eat grass, and;

2. Milk comes from cows, to;

3. Milk is made of grass.

That inference is certainly much more questionable, but it's not entirely wild. A little imagination will give it, too, considerable plausibility. One needs to have the idea that the cow is, so to speak, a milk-producing machine. The cow eats grass, processes it in her belly, and turns it into the product, milk. In fact, further questioning of the child I've called "Maxine" showed that such was, in fact, that child's idea. (Teacher: "Why isn't cheese green?" Child: "When the cows eat grass it goes into 
their stomach and then gets changed around and comes out milk. The milk is made in the cow's stomach." What a neat and plausible account of what goes on in the belly of the cow!)

Some people, influenced, perhaps, by Piaget, would insist that no child under the age of eight (as the child I have re-named "Maxine" was) could understand or use a transitivity principle, such as the principle that if $A$ is made of $B$ and $B$ is made of $C$, then $A$ is made of $C$. I asked my students if they were reluctant to attribute such reasoning to Maxine because of her young age. They said "No," though perhaps with some hesitation. So why did they think there must be a mistake in her reasoning?

I think the explanation is this. Adults in our society, and especially teachers and "sophisticated" parents, suppose children go through stages of cognitive development. We may not be clear as to exactly what these stages are or exactly what limitations they impose. Thus, we may not be clear as to when children are first able to use transitivity principles. But almost everyone agrees that young children operate under severe cognitive limitations. If they say something odd and unexpected, it is therefore a good bet that the oddity is the result of a cognitive limitation, a conceptual mistake or an error in reasoning.

The importance of this idea of cognitive limitations needs emphasis. The idea is not just that the child of three or five or seven will lack certain information, information that, perhaps, the teacher or parent could supply. It's not even that the child's experience is so limited that the child will not take into consideration aspects or factors that an older and more experienced person would naturally consider. The idea is that the child's conceptual and reasoning structure will be limited in ways that keep the child from thinking the way "we" do, where "we," obviously, have mature and well-formed conceptual and reasoning structures at our disposal. So, on this developmental assumption, it is inevitable that the child will make what, from our adult point of view, are odd mistakes, mistakes that can be corrected only by a process of mental maturation that, even if it can be encouraged and speeded up slightly, cannot be successfully rushed.

Suppose that we, like most "sophisticated" adults in our society, accepted this developmental assumption. Then we would suppose that a child under eight is at a fairly early stage of cognitive development. If then, we encountered such a child who said something strange, such as "Cheese is made of grass," we would naturally suppose the child to be handicapped by some primitive conception, or by some inadequate form of reasoning, or by both. The assumption of primitivity that goes with the idea of cognitive development thus discourages adults from listening to what children actually say. If we listen, this assumption encourages us to filter what children say through the condescending assumption of primitivity.

Who cares whether the made-of relation is transitive? 
The only adults in our society who are likely to give much thought to this question are philosophers. A philosopher might write an article, or a chapter of a book, on it-supported, perhaps, by a fellowship from the National Endowment for the Humanities. In assuming, almost automatically, that Maxine has made some mistake and in, thus, missing the chance to think about whether, if $A$ is made of $B$ and $B$ is made of $C$, $\mathrm{A}$ is made of $\mathrm{C}$, one is missing a chance to do philosophy with Maxine. That is what the students in my class missed. And that is what adults in their encounters with children miss over, and over, and over again.

Matthew Lipman recently asked me to review a book called Wally's Stories (Harvard, 1981) for his journal, Thinking. ${ }^{2}$ The author of the book, Vivian Gussin Paley, is a remarkably imaginative kindergarten teacher who was so interested in the discussions of her class and so anxious to follow up on them that she tape-recorded them and transcribed them later the same day-before the discussion had faded in her memory and in time to think about a follow-up the next day, if that should be called for. The book contains many extended excerpts from those discussions. They are wonderful. The kids are imaginative, playful, inventive and remarkably free. The freshness of these discussions is a profound tribute to the teacher who made them happen.

Still, there is a curiously disappointing aspect to the book. The teacher's commentary shows remarkably little insight into, or appreciation for, the children's point of view. Some of the freshest and most intriguing conversational fragments are followed by quite unilluminating comments. Consider this exchange, which takes place after the class has planted lettuce seeds:

Eddie: ... how do we know it's really lettuce?

Teacher: The label says "Bibb Lettuce."

Eddie: What if it's really tomatoes?

Teacher: Oh. Are you wondering about the picture of tomatoes with the lettuce on the packet? It's just an idea for salad, after the lettuce comes up.

Warren: They might think they're lettuce seeds and they might not know.

Earl: Maybe the seeds look the same as something else.

Teacher: Do you think they could make such a mistake?

Lisa: Just bring it back to the store if it's wrong.

Deana: The store people didn't even make it.

Eddie: You have to take it back to the gardener.

Deana: Maybe they printed a word they wanted to spell the wrong way. Maybe they mixed it up.

Eddie: They could have meant to put different seeds in there and then they turned around and went to the wrong table.

Wally: The wrong part of the garden. The tomato part.

Warren: So in case it's not lettuce it could be tomatoes (pp. 183-4). 
Eddie's question is about evidence and the warrant for knowledge. The other children join in immediately; they happily think of various possibilities that tend to undermine the justification we might have thought we had for believing that those seeds were indeed lettuce seeds. In this way they call into question the claim to knowledge.

Anyone who has taught a course in philosophy will be familiar with the idea of raising questions that tend to undermine our claim to know such things as that the seeds in that packet are lettuce seeds. Once doubts have been raised, is there any way to dismiss them, rationally and responsibly? Is there perhaps some conceivable evidence such that, if we had it, we would have an unshakable claim to know that those little things are indeed lettuce seeds? Or suppose there is no such thing. Is the consequence that nobody ever really knows that certain things are lettuce seeds?

My family was recently visited by someone who had grown up and spent most of her life in cities. We planned a picnic. Our visitor was pleased. But when we suggested taking berry boxes along on the picnic so that we could pick wild blueberries, our visitor was upset. "How will I know they are edible?" she wanted to know. "That's easy," we said; "we'll tell you." Our visitor was not reassured. "You'll put me in the awkward position," she said, "of having to choose between offending you (by refusing to eat what you tell me is edible) and accepting something I have insufficient evidence for." We reflected. "But how do you know to believe the labels on the berries you buy in the store?" we asked, pleased with our response. Her response was quick. "I've had lots of experience eating those," she replied, smiling at herself.

As you can tell, I would like to do philosophy with Vivian Paley's kindergarten class. I would like to puzzle out with them whether we know, and if so, how we know, that those little seeds are lettuce seeds. I was, as you can imagine, severely disappointed with this comment from the teacher:

There was no suggestion of robbers or magicians; human error was the only factor considered. The ideas for distributing the lettuce crop were equally practical. (p. 184)

Equally practical! As a philosopher I'm offended at that assessment. What in the world is practical about thinking of ways in which it could turn out that seeds in a perfectly ordinary (or at least apparently perfectly ordinary!) lettuce-seed package might fail to contain lettuce seeds, especially when the matter at stake is whether we know these are lettuce seeds? Here surely is the beginning of pure philosophy-with nothing practical in sight. Though her book is filled with similar beginnings, Vivian Paley never seems to recognize or encourage them. Why not? It's not because she doesn't care about the kids. She certainly does care; in fact, she obviously cares deeply. It's not even because she doesn't care about their thinking. It's because, I think, the only way she knows to take an interest in the thinking of children is to 
take an interest in its development, where, automatically, she assumes that the thinking of kindergarteners will be primitive and making it develop will just be making it indistinguishable from standard adult thinking. (What a standard!) Thus, here is the opening statement from the appendix to her book:

Each year I come closer to understanding how logical thinking and precise speech can be taught in the classroom. These skills are, I believe, the important percursors to formal schooling and the main business of the kindergarten teacher. The book describes my search for the child's point of view with which I can help him take a step further. (p. 213)

As Vivian Paley herself admits, she has not come very close to finding the child's point of view. But that, perhaps, is not so much because the child is handicapped by a primitive mentality that is difficult for us adults to understand. Rather, I suggest, it is more because the child, being not yet socialized to turn aside naive questions, is more openly philosophical than we are. By filtering the child's remarks through our developmental assumptions we avoid having to take the philosophy in those remarks seriously; that way we also avoid taking the child and the child's point of view with either the seriousness or the playfulness they deserve.

Early on in a section called "Man in the Moon" Paley remarks, scornfully, "Inconsistency is the norm, even in wishing" (p. 62). There then follows the transcript of a delightful and highly ingenious discussion on whether there is a man in the moon and, if there is, how he can be there. Here are parts of it:

Earl: My cousin says you can wish on the man in the moon. I told my mother and she says it's only pretend.

Lisa: He's not real.

Deana: But how could he get in?

Wally: With a drill.

Eddie: The moon won't break. It's white like a ghost. The drill would pass in but no hole will come out.

Kenny: There is a face but my daddy says when you get up there it's just holes. Why would that be?

Deana: Somebody could be up there making a face and then when somebody goes up there he's gone.

Fred: There can't be a moon man. It's too round. He'd fall off.

Wally: He can change his shape. He gets rounder.

Eddie: The astronauts didn't change their shape ...

Fred: I saw that on television. They were walking on the moon. But a real moon man would have to find a door. And if you fall in a hole you'll never get out.

Wendy: Sure you can, when the moon is a tiny piece. 
Warren: There is such a thing as a half moon. But the astronauts can't be cut in half. They can only go when it's round. A moon man can squeeze in half.

Eddie: There's no air there. No air! But air is invisible so how can there be no air?

Wally: Only the moon man sees it.

Tanya: Maybe there's a moon fairy, because some fairies are white that you could see through (p. 63-4).

What a marvelous discussion! (Without even a word from the teacher!) What wonderfully fresh ideas!

Imagine trying to reason out, with little knowledge of physics or astronomy, whether there could be a man in the moon. Imagine trying to put together (1) TV shots of astronauts walking on the moon, (2) pictures in books or newspapers of moon craters, (3) nursery-rhyme illustrations of the man in the moon, and (4) various nighttime and, especially, day-time appearances of that mysterious object in the sky. Think about what could happen to the man in the moon when there is only a half-moon. Think about a region where there is nothing of something that, even where there is some of it, is invisible. Think about what something as wraithlike as the daytime moon might be made of.

Immediately following this lovely moon passage, the teacher comments, as if in summary judgment, "The credo at age five is to believe that which makes you feel good" (p. 64). What a letdown! How can an adult, who sets the stage for such a beautiful discussion and records it faithfully for our great delight and instruction, see so little of its virtuosic ingenuity?

We tell our children wonderful tales of myth and magic. Then we invite them to reconcile fantasy with reality. When they fail, as we know they will, we sternly call them inconsistent. Why?

Eventually I convinced my Boston class that there is often interesting reasoning to be found in the remarks of children, even in the remarks of very young children. But I'm not sure I convinced all of them that they should sometimes take the occasion of a child's remark to do some philosophy with the child. book:

Later on in the course I gave them this anecdote from Vivian Paley's

Lisa: Do plants wish for baby plants?

Deana: I think only people can make wishes. But God could put a wish inside a plant.

Teacher: What would the wish be?

Deana: What if it's a pretty flower? Then God puts an idea inside to make this plant into a pretty red flower-if it's supposed to be red.

Teacher: I always think of people having ideas.

Deana: It's just the same. God puts a little idea in the plant to tell it what to be. 
Again I asked my students how they might continue the conversation. In general they were willing to encourage free discussion. But they weren't inclined to take the occasion to examine, say, their own concept of a wish to try to make clear to themselves, if not to Lisa, exactly what might make it appropriate and what may make it inappropriate to speak of wishes of plants. Most of them were inclined to suppose that wishes have to be conscious and that plants are not conscious, so, though perhaps it is all right to let Lisa project human feelings onto plants, there is no serious issue here to be discussed by us adults. Frustrated by their insensitivity to a range of issues that interests and excites me a great deal, I wrote a dialogue myself, attached the names of members of my class to the speeches of the dialogue and then had my students read their parts out loud on the next meeting of the class. Here is the dialogue I wrote:

Gary: Well, do plants wish for baby plants?

Jane: I have a plant that wants plenty of sunshine and another that really wants shade.

Jane: That's just a way of talking. What you mean is that the first plant does well in sunshine and the other does better in shade.

Diane: But sometimes plants want to do something. For example, I had a Morning Glory that grev right up the side of the house until it got to the gutter. It bent around the gutter and tried to find a higher place to stick onto. It just wavered around there trying to find a higher place. It wanted to go higher.

Peter: It has a hormone or something that makes it go up.

Cindy: I know a person who had to take medicine to prevent her having migraine headaches. The medicine gave her an enormous appetite. Though it was the medicine that gave her the appetite, she really wanted the food.

Peter: Did she really want the food?

Cindy: Well, she didn't want to get fat. But even after she had eaten a big meal, she was still hungry.

Gary: Having conflicting desires-like wanting food but not wanting to get fat-doesn't mean the desires aren't real.

David: With plants you can always cash in this "want" talk as tendencies. The Morning Glory tends to grow up and will do so as long as there is a suitable object for it to adhere to.

Betty: Can't you do that with people, too? A hungry person will tend to eat, as long as there is food around.

John: But there is more to it with people. They can tell you what they want.

Sally: Sometimes. Sometimes they don't know what they want. They may have to go to a "shrink" to find out.

Elaine: And what about small babies? When my baby cries three or four hours after the last feeding, she wants milk. She can't tell me thatexcept by crying.

Marie: Crying is a way of telling somebody you are hungry. When the baby grows up she'll learn other ways, but crying is a way of telling. 
Linda: Couldn't shriveling up your leaves be a way of telling sombody that you want more water? Of course the plant never learns any other way, but maybe shriveling up your leaves is a way of telling somebody you are thirsty.

Shari: From an evolutionary point of view there might be a similarity. Plants that showed no signs of drying up until they were already dead would't, maybe, get looked after as well as those that did and so they would fail to propagate themselves. In the same way babies that didn't cry like bloody murder would't get fed.

Billie Jean: But the main thing that let us talk about the desires of human babies, even newborns, is that we know the babies will naturally grow up to become human adults who can talk about their own desires. That process of growing up is such a smoothly continuous one that it seems arbitrary to pick some point at which a child first has desires.

Gary: But of course there is an analogy between the development of a human individual (ontogeny) and the evolutionary development of the species (phylogeny). The phylogenetic scale exhibits enough continuity that it may seem arbitrary to pick a point along it where there are first real desires. Some things chimps do are like things people do because of desires they have. Some things dogs do are like the "desire" - expressing behavior of chimps. Some things frogs do are like the "desire" - expressing behavior of dogs-etc., all the way down through micro-organisms to plants.

So, what do you think? Do plants wish for baby plants?

Michael: It's a nice idea.

Dawn: I could write a poem about it.

Gary: But do they really?

Richard: Weil — sort of, they do, and sort of, they don't.

Gary: What are the respects in which they do and what are the respects in which they don't?

Richard: That's hard.

My dialogue got through to some of my students, but not by any means to all, perhaps not to most. It was hard for them to examine the concept of a wish in the way this dialogue was meant to prod them to do. It's easier to approach the remarks of children under the protection of our condescending assumptions. Children do grow up. Adults, most of them, are quite unlikely to talk out loud about the wishes of plants. So why bother oneself with Lisa's remark? Lisa will grow out of saying things like that.

But suppose what Lisa says constitutes an invitation to do philosophy? Then the assurance that children do, after all, grow up is misplaced unless, of course, you are reassured by being told that you won't have to go on doing philosophy through adult life. I'm not. Nor am I reassured by the thought that there are scores of philosophically interesting comments made by children every day to which the best adult response is likely to be a misconceived effort to get the child to grow up. 


\section{Notes}

1. This article was presented at the Phenomenology of Childhood Conference, University of Michigan, April, 1982. Parts of these remarks were first prepared for a conference at William Paterson College on November 20,1981; that conference, which was organized by Marie L. Friquegnon, was entitled "Philosophy and the Child: New Perspectives."

2. The comments on Vivian Paley's book, Wally's Stories, are adapted from my review in Thinking, vol. 3, nos. 3/4, 1981-2, 78-80. 